\title{
Comparative study of safety and efficacy of pregabalin, gabapentin and amitriptyline in management of neuropathic pain
}

\author{
Nagaraju Kancherla $^{1}$, G. Chitti Babu ${ }^{2 *}$, Hukum Singh $^{3}$, Mayank Khandelwal ${ }^{2}$, \\ Nitika Sharma ${ }^{2}$, Masuram Bharath Kuma ${ }^{4}$
}

\author{
${ }^{1}$ Department of Pharmacology, GSL Medical College and General Hospital, Rajahmundry, Andhra Pradesh, India \\ ${ }^{2}$ JNU Medical College and Hospital, Jagathpura, Jaipur, Rajasthan, India \\ ${ }^{3}$ Associate Professor, Department of Pharmacology, JNU Institute of Medical Sciences and Research Center, Jaipur, \\ Rajasthan, India \\ ${ }^{4}$ Varun Arjun Medical College, Banthra, Shahjahanpur, Uttar Pradesh, India
}

Received: 28 October 2020

Accepted: 02 December 2020

*Correspondence:

Dr. G. Chitti Babu,

Email: chandu.young@gmail.com

Copyright: ( $)$ the author(s), publisher and licensee Medip Academy. This is an open-access article distributed under the terms of the Creative Commons Attribution Non-Commercial License, which permits unrestricted non-commercial use, distribution, and reproduction in any medium, provided the original work is properly cited.

\begin{abstract}
Background: Neuropathic pain has a significant negative impact on the patients' quality of life. Now a day's anticonvulsants and antidepressants drugs are often used as first-line drugs for the treatment of neuropathic pain. The present study aims to evaluate the safety and efficacy of gabapentin, amitriptyline, and pregabalin in patients of severe neuropathic pain not controlled by simple analgesics.

Methods: A total of 360 patients diagnosed with cases of chronic lumbar radiculopathy based on symptoms, clinical examination, X-ray, and magnetic resonance imagining (MRI) scan of the lumbosacral spine, were randomized into three groups. Group A patients received pregabalin $75 \mathrm{mg}$, Group B patients received gabapentin $300 \mathrm{mg}$, and Group $\mathrm{C}$ patients received amitriptyline $10 \mathrm{mg}$, respectively. Pain intensity was measured at the baseline, after 1 month and after 2 months with the Numeric pain rating scale (NPRS). Adverse drug reaction reported by the patient or observed by the clinician during the study was reported using the adverse drug reaction (ADR) reporting form.

Results: At baseline, the mean \pm SD of NPRS score in Group A was 8.42 \pm 1.48 , in Group B and Group C were 8.53 \pm 1.94 and $8.33 \pm 1.26$ respectively with an F-value of 0.843 and p value of 0.584 , which was not statistically significant. At 1 month, the mean \pm SD of NPRS score in Group A was 7.23 \pm 1.58 , in Group B and Group C were 7.43 \pm 2.03 and $7.99 \pm 2.10$ respectively with $\mathrm{F}$-value of 1.58 and $\mathrm{p}$ value of 0.085 which was not statistically significant. At 2 months, the mean \pm SD of NPRS score in Group A was 4.38 \pm 2.72 , in Group B and Group C were 4.74 \pm 2.86 and 6.32 \pm 2.31 respectively with F-value of 5.53 and $p$ value of 0.002 which was statistically significant.

Conclusions: Pregabalin has the advantages in terms of the NPRS score over gabapentin and amitriptyline. Gabapentin has fewer reported adverse effects and hence better patient compliance on long term use. Amitriptyline is more cost effective than pregabalin which is an important factor to keep in mind while treating patients.
\end{abstract}

Keywords: Gabapentin, Amitriptyline, Pregabalin, Neuropathic pain

\section{INTRODUCTION}

Neuropathic pain $(\mathrm{NeP})$ is triggered by a lesion or a disease affecting the somatosensory nervous system that alters its structure and function, so that pain occurs spontaneously and responses to noxious and innocuous stimuli are pathologically amplified. ${ }^{1}$ Peripheral causes of $\mathrm{NeP}$ are for example, polyneuropathy, post herpetic neuralgia, postoperative pain, and posttraumatic neuralgia, while causes of central NeP are spinal cord injuries and stroke. ${ }^{2}$ Recently revised the worldwide applied NeP 
pharmacotherapy recommendations from the special interest group on neuropathic pain concluding that there was a strong Grades of recommendation assessment, development and evaluation (GRADE) recommendation for use and proposal as first-line treatment for tricyclic anti-depressants (TCA), serotonin and norepinephrine reuptake inhibitors (SNRIs), pregabalin, and gabapentin. ${ }^{3}$

Pregabalin, is a well-established anticonvulsant and analgesic agent. Pregabalin is the first drug to receive approved labelling from Food and Drug Association (FDA) for the treatment of neuropathic pain and postherpetic neuralgia. ${ }^{4}$ Preclinical and clinical studies have shown the effectiveness of pregabalin in managing the neuropathic pain. Animal based studies have helped to describe the mechanisms for its anti-hyperalgesia and antiallodynia action. ${ }^{5}$ Clinical studies have also shown the efficacy and dose dependent effects of pregabalin either as monotherapy or in combination with analgesics in relieving pain and related symptoms. The major advantage of pregabalin is its relative reliability, easy use and high tolerance in patients with neuropathic pain. ${ }^{6}$

Gabapentin (GBP) is a commonly used for post-herpetic neuralgia (PHN). The mechanism of action for GBP relates to its ability to bind with high-affinity to the alpha2-delta subunit of voltage-gated calcium channels located throughout the peripheral and central nervous system; thus, modifies the release of neurotransmitters and reduces excitability of nerve cells. ${ }^{7}$ It is this mechanism of action that may produce analgesic effect in patients experiencing neuropathic pain. ${ }^{8}$

Amitriptyline is a tricyclic antidepressant that is widely used to treat chronic neuropathic pain. The mechanism of action of amitriptyline in the treatment of neuropathic pain remains uncertain, although it is known to inhibit both serotonin and noradrenaline reuptake. ${ }^{9}$ The mechanism is likely to differ from that in depression since analgesia with antidepressants is often achieved at a lower dosage than the onset of any antidepressant effect; adverse events associated with amitriptyline often wane after two or three weeks, when the benefits of the drug become apparent. ${ }^{10}$ In addition, there is no correlation between the effect of antidepressants on mood and pain, and antidepressants produce analgesia in people with and without depression. ${ }^{11}$

\section{METHODS}

\section{Study design}

Present study was prospective, comparative, open label, single centre, three arm study.

\section{Study centre}

Study was conducted at outpatient Orthopaedics department in collaboration with Department of Pharmacology, JNU Medical College and Hospital.

\section{Study design}

Total patients were 360 and were randomized into 3 groups. Group A patients received pregabalin $75 \mathrm{mg}$. Group B patients received gabapentin $300 \mathrm{mg}$. Group C patients received amitriptyline $10 \mathrm{mg}$.

\section{Inclusion criteria}

Either sex with an age group of 18-65 years. Diagnosed cases of chronic lumbar radiculopathy based on symptoms, clinical examination, X-ray and magnetic resonance imaging (MRI) scan of the lumbosacral spine. Patient willing to participate in the study and able to give written and informed consent.

\section{Exclusion criteria}

Patients with a history of diabetes, tuberculosis, cardiac illness, renal and liver diseases. Pregnant and lactating women. Patients who are immunocompromised. Patients having radiculopathy secondary to tumors. Patients with known hypersensitivity to the study drugs.

\section{Study conduct}

Brief description of the procedure in the study: consenting patients were initially screened for the diagnosis and eligibility. After getting enrolled and prior to the commencement of the treatment, the following were recorded in the case record form-physical examination, systemic examination, vital signs, past medical history, concomitant medications if any, clinical tests for chronic lumbar radiculopathy, $x$-ray of lumbosacral spine-AP and lateral views (digital-AGFA x-ray machine), MRI scans of lumbosacral spine (GE made MRI scan machine -1.5 tesla), pain assessment was done using numeric pain rating scale (NPRS) at the start of the study (0 day), at 1 months and at 2 months.

\section{ADR reporting}

Adverse drug reaction reported by the patient or observed by the clinician during the study was reported using the ADR reporting form.

\section{Statistical analysis}

For analysis of this data Statistical package for social science (SPSS) software version 20th was used. Qualitative data were represented in the form of values and percentages. Quantitative were represented in the form of mean \pm SD. For comparison between three groups mean pain on numerical pain rating scale ANOVA was used. Also for comparison between two groups at different time intervals Tukey Post Hoc test was used. Chi square test was used to evaluate adverse drug reactions in all the three study groups. $\mathrm{P}$ value was checked at $5 \%$ level of significance. 


\section{RESULTS}

In each group total 120 patients were there. In Group A: 68 $(56.7 \%)$ were females and $52(43.3 \%)$ were males. In Group B: 65 were females $(54.7 \%)$ and 55 (45.3\%) were males. In Group C: 71 were females (59.7\%) and 49 $(40.3 \%)$ were males.

Table 1: Distribution of patients according to gender.

\begin{tabular}{|llll|}
\hline Gender & Group A & Group B & Group C \\
\hline Male & $52(43.3 \%)$ & $55(45.3 \%)$ & $49(40.3 \%)$ \\
\hline Female & $68(56.7 \%)$ & $65(54.7 \%)$ & $71(59.7 \%)$ \\
\hline Total & $120(100 \%)$ & $120(100 \%)$ & $120(100 \%)$ \\
\hline
\end{tabular}

Table 2: Distribution of patients according to age group.

\begin{tabular}{|llll|}
\hline $\begin{array}{l}\text { Age- } \\
\text { group }\end{array}$ & Group A & Group B & Group C \\
\hline $\mathbf{1 8 - 4 0}$ & 26 & 23 & 27 \\
\hline $\mathbf{4 1 - 6 0}$ & 48 & 49 & 43 \\
\hline$>\mathbf{6 1}$ & 46 & 48 & 50 \\
\hline Total & 120 & 120 & 120 \\
\hline Mean \pm SD & $42.32 \pm 8.32$ & $43.48 \pm 7.48$ & $44.48 \pm 7.52$ \\
\hline F-value & 0.339 & & \\
\hline p value & $0.632^{\text {ns }}$ & & \\
\hline
\end{tabular}

Table 3: Comparison of NPRS score in all three groups at baseline after 1 months and after 2 months

(ANOVA).

\begin{tabular}{|c|c|c|c|c|}
\hline & & Mean \pm SD & $\begin{array}{l}\text { F } \\
\text { value }\end{array}$ & $\begin{array}{l}\mathbf{P} \\
\text { value }\end{array}$ \\
\hline \multirow{3}{*}{ Baseline } & Group A & $8.42 \pm 1.48$ & \multirow{3}{*}{0.843} & \multirow{3}{*}{$0.584^{\mathrm{ns}}$} \\
\hline & Group B & $8.53 \pm 1.94$ & & \\
\hline & Group C & $8.33 \pm 1.26$ & & \\
\hline \multirow{3}{*}{$\begin{array}{l}\text { After } 1 \\
\text { month }\end{array}$} & Group A & $7.23 \pm 1.58$ & \multirow{3}{*}{1.58} & \multirow{3}{*}{$\begin{array}{l}0.085 \\
\mathrm{~ns}\end{array}$} \\
\hline & Group B & $7.43 \pm 2.03$ & & \\
\hline & Group C & $7.99 \pm 2.10$ & & \\
\hline \multirow{3}{*}{$\begin{array}{l}\text { After } 2 \\
\text { months }\end{array}$} & Group A & $4.38 \pm 2.72$ & \multirow{3}{*}{5.53} & \multirow{3}{*}{$0.002^{\mathrm{s}}$} \\
\hline & Group B & $4.74 \pm 2.86$ & & \\
\hline & Group C & $6.32 \pm 2.31$ & & \\
\hline
\end{tabular}

In Group A: the mean age of patients was $42.34 \pm 8.32$ years. In group B: the mean age of patients $43.48 \pm 7.48$ years. In group $\mathrm{C}$ : the mean age of patients was 44.48 \pm 7.52 . The F-value was 0.339 and the $p$ value 0.632 which was statistically not significant.

At baseline, the mean \pm SD of NPRS score in Group A was $8.42 \pm 1.48$ in Group B and Group C were $8.53 \pm 1.94$ and $8.33 \pm 1.26$ respectively with an F-value of 0.843 and $p$ value of 0.584 which was not statistically significant. At 1 month, the mean \pm SD of NPRS score in Group A was $7.23 \pm 1.58$, in Group B and Group C were 7.43 \pm 2.03 and $7.99 \pm 2.10$ respectively with an F-value of 1.58 and $p$ value of 0.085 which was not statistically significant. At 2 months, the mean \pm SD of NPRS score in Group A was $4.38 \pm 2.72$, in Group B and Group C were 4.74 \pm 2.86 and $6.32 \pm 2.31$ respectively with an $F$-value of 5.53 and $p$ value of 0.002 which was statistically significant.

Table 4: Comparison of NPRS score in tow groups at baseline, 1 month and 2 months (Tukey post hoc test).

\begin{tabular}{|llll|} 
& & $\begin{array}{l}\text { Mean } \\
\text { SD }\end{array}$ & P value \\
\hline \multirow{2}{*}{ Baseline } & Group A versus B & 0.22 & $0.635^{\mathrm{ns}}$ \\
\cline { 2 - 4 } & Group A versus C & 0.19 & $0.724^{\mathrm{ns}}$ \\
\cline { 2 - 4 } & Group B versus C & 0.21 & $0.739^{\mathrm{ns}}$ \\
\hline \multirow{2}{*}{$\begin{array}{l}\text { After 1 } \\
\text { months }\end{array}$} & Group A versus B & 0.87 & $0.439^{\mathrm{ns}}$ \\
\hline \multirow{2}{*}{$\begin{array}{l}\text { Group A versus C } \\
\text { month 2 }\end{array}$} & $\begin{array}{l}\text { Group B versus C } \\
\text { Group A versus B }\end{array}$ & 0.99 & $0.059^{\mathrm{s}}$ \\
\hline & Group A versus C & 1.54 & $0.421^{\mathrm{ns}}$ \\
\hline & Group B versus C & 1.69 & $0.453^{\mathrm{ns}}$ \\
\hline
\end{tabular}

Table 5: Comparison of percent reduction of NPRS score baseline versus after 2 months in all three groups.

\begin{tabular}{|lll|}
\hline Group & $\begin{array}{l}\text { Mean } \\
\text { reduction }\end{array}$ & $\begin{array}{l}\% \text { mean } \\
\text { reduction }\end{array}$ \\
\hline $\begin{array}{l}\text { Group A at baseline versus } \\
\text { Group A at } 2 \text { months }\end{array}$ & 5.63 & $53.74 \%$ \\
\hline $\begin{array}{l}\text { Group B at baseline versus } \\
\text { Group B at 2 months }\end{array}$ & 5.84 & $51.57 \%$ \\
\hline $\begin{array}{l}\text { Group C at baseline versus } \\
\text { Group C at 2 months }\end{array}$ & 4.21 & $33.39 \%$ \\
\hline
\end{tabular}

The mean reduction of NPRS pain score in Group A from baseline to 2 months was 5.63 with a percent mean reduction of NPRS pain score of $53.74 \%$. The mean reduction of NPRS pain score in Group B from baseline to 2 months was 5.84 with a percent mean reduction of NPRS pain score of $51.57 \%$. The mean reduction of NPRS pain score in Group C from baseline to 2 months was 4.21 with a percent mean reduction of NPRS pain score of $33.39 \%$.

In the present study, the occurrence of dizziness was significantly more in group B with 32 patients $(26.66 \%)$ as compared to group A with 23 patients (19.16\%) and group $\mathrm{C}$ with 13 patients $(10.83 \%),(\mathrm{p}=0.054)$. The sedation occurred in 37 patients of group B $(30.83 \%)$, which was significantly more than group A i.e., in 34 patients $(28.33 \%)$ and group C i.e. 31 patients $(25.83 \%),(\mathrm{p}=0.042)$.

The occurrence of constipation was seen in 13 patients of group C (10.83\%) which was significantly more than in Group A and B $(\mathrm{p}=0.026)$. The occurrence of dryness of mouth was significantly more in group $\mathrm{C}$ with 19 patients $(15.83 \%)$ as compared to that of Group A and B ( $\mathrm{p}=0.000)$. 
Table 6: Adverse drug reaction in patients in all three groups.

\begin{tabular}{|lllllllll|l|} 
& Group A & \multicolumn{4}{c}{ Group B } & \multicolumn{3}{c|}{ Group C } & \multicolumn{2}{c|}{ Chi- } & P value \\
\hline Dizziness & $\mathbf{n}$ & $\mathbf{\%}$ & $\mathbf{n}$ & $\mathbf{\%}$ & $\mathbf{n}$ & $\mathbf{\%}$ & square & 0.054 \\
\hline Sedation & 23 & 19.16 & 32 & 26.66 & 13 & 10.83 & 4.47 & 0.042 \\
\hline Constipation & 34 & 28.33 & 37 & 30.83 & 31 & 25.83 & 6.69 & 0.026 \\
\hline Dry mouth & 0 & 00 & 0 & 00 & 13 & 10.83 & 7.47 & 0.026 \\
\hline
\end{tabular}

\section{DISCUSSION}

The results of present study indicate a female preponderance in both the treatment groups which is different from other studies which have reported a male predominance. $^{12}$ This could be probably due to geographical variations or less pain threshold and emotional liability of females.

Patients, who received amitriptyline, had an expected pain score reduction and the pain relief was noted within 5-6 days after starting the treatment. Those patients who received pregabalin also showed a good pain score reduction which is comparable to that of the other studies and pain relief was reported from 4 days of the starting treatment. In addition, amitriptyline also had good compliance. According to Bansal et al study from India also reported that pregabalin has a much faster and better pain relief compared to gabapentin. ${ }^{13}$ Few other placebos controlled studies conducted with pregabalin for a period of five and eight weeks have documented a significant reduction in pain compared to placebo $(\mathrm{p}<0.001){ }^{14}$

Kaur et al conducted a study on amitriptyline for neuropathic pain in a dose of $10 \mathrm{mg}$ to $100 \mathrm{mg}$ per day. ${ }^{15}$ Certain guidelines suggest that amitriptyline can be started at $10 \mathrm{mg}$ and can be titrated up to $150 \mathrm{mg}$ at bed time to treat neuropathic pain. ${ }^{16,17}$ In the present study amitriptyline dose is $10 \mathrm{mg}$ HS. This is comparable and coincides with the similar studies conducted in India earlier and this also signifies that in Indian patients the dose of amitriptyline needed to treat neuropathic pain is $10-50 \mathrm{mg}$.

Ghosh et al evaluated the efficacy and safety of pregabalin for the treatment of neuropathic pain have used the plain pregabalin capsules and all these studies have concluded that the recommended dose of pregabalin for neuropathic pain is $300 \mathrm{mg}$ to $600 \mathrm{mg}$ per day in two or three divided doses. ${ }^{18}$ In the present study pregabalin at $75 \mathrm{mg}$ HS started initially and according to the patient's need the dose was titrated upwards. This is one of the main advantages of sustained release preparation that it has a once daily dosing schedule which may decrease the adverse effects and increase the patient compliance. Two other Indian studies have also used plain pregabalin capsules at a dose of 75$150 \mathrm{mg}$ per day to treat neuropathic pain and found to be efficacious. ${ }^{19}$ Another recent multicentre study conducted in India, with the sustained release of pregabalin and methylcobalamin has also demonstrated that pregabalinSR $(75-150 \mathrm{mg})$ has significantly reduced the neuropathic pain at a lower than recommended doses (150-600), in Indian patients, with an advantage of lesser adverse effects. ${ }^{20}$ This difference in dose is difficult to explain and may need further studies in larger number of patients. It is being reported from few recent studies that Indian patients, probably Asian's too need lower doses of Pregabalin, particularly when used as a sustained release formulation to achieve the therapeutic goal with lesser adverse effects. ${ }^{21}$

The pain reduction in patients treated with pregabalin was $53.74 \%$ with gabapentin it was $51.57 \%$ and with amitriptyline it was $33.39 \%$ at the end of 2 months. Hence, pregabalin showed comparable pain reduction as compared to gabapentin $(53.74 \%$ versus $51.57 \%)$ at the end of 2 months of study. Dongre et al reported that results from randomized trials support the superior efficacy of pregabalin when compared to gabapentin, which is in contrast to the present study. ${ }^{22}$ Pregabalin was more efficacious than amitriptyline (53.74\% versus $51.57 \%)$ in reducing pain at the end of 2 months of study. This effect can be attributed to the agonistic action on a subset of GABAB receptors which negatively regulates the alpha-2delta subunit of voltage gated $\mathrm{Ca} 2+$ channels, activate inwardly rectifying $\mathrm{K}+$ channels, blocks $\mathrm{Ca} 2+$ and $\mathrm{Na}+$ channels and open $\mathrm{K}+$ channels which leads to inhibition of the abnormal activity and hyper-excitability of sensory neurons, thereby reducing pain. ${ }^{23}$

The safety and tolerability studies did not show any unusual or severe adverse events in the present study. The dose limiting adverse effects remain a major problem for patients' with neuropathic pain. The tolerability profile in this study was generally consistent with the previous studies. ${ }^{24}$ Patients who took amitriptyline reported mainly dry mouth and drowsiness and was more with patients who took $50 \mathrm{mg}$ HS. Very few patients who took pregabalin complained of drowsiness and only 2 patients out of 40 had complaints of dizziness. The reported number of adverse events was less with pregabalin SR in this study.

Strength of the present study is, standard validated scales and scores for the diagnosis of neuropathic pain and for assessing the primary outcome measure pain relief. Authors have applied percentage reduction in the primary efficacy parameter to analyse the difference between the two groups. To the best of our knowledge, not many studies 
have used percentage reduction, which is more sensitive to less number of patients than the simple absolute values. There have been a few limitations in this study. This was an open label study without any blinding. The follow-up of patients was only for 2 months and therefore, the long-term efficacy and safety of the study drugs could not be assessed.

\section{CONCLUSION}

Thus, in conclusion three groups gabapentin, pregabalin and amitriptyline are equally efficacious in relieving pain in NeP. Pregabalin has the advantages in terms of NPRS score over the gabapentin and amitriptyline. Gabapentin has fewer reported adverse effects and hence a better patient compliance on long term use. Amitriptyline is more cost effective than pregabalin which is an important factor to keep in mind while treating patients.

Funding: No funding sources

Conflict of interest: None declared

Ethical approval: The study was approved by the Institutional Ethics Committee

\section{REFERENCES}

1. Costigan M, Scholz J, Woolf CJ. Neuropathic Pain. A Maladaptive Response of the Nervous System to Damage. Annu Rev Neurosci. 2009;32:1-32.

2. Attal N, Gruccu G, Baron R, et al. EFNS guidelines on the pharmacological treatment of neuropathic pain: 2010 revision. Eur J Neurol. 2010;17(9):1113-23.

3. Finnerup NB, Attal N, Haroutounian S, et al. Pharmacotherapy for neuropathic pain in adults: a systematic review and meta-analysis. Lancet Neurol. 2015;14(2):162-73.

4. Arnold L., Russell I., Diri E., Duan W., Young J., Jr, Sharma U., et al. . (2008) A 14-week, randomized, double-blinded, placebo-controlled monotherapy trial of pregabalin in patients with fibromyalgia. J Pain 9: 792-805.

5. Campbell JN, Meyer RA. Mechanisms of neuropathic pain. Neuron. 2006;52:77-92.

6. Nascimento OJ, Pessoa BL, Orsini M, Ribeiro P, Davidovich E, Pupe C, et al. Neuropathic pain treatment: still a challenge. Neurol Int. 2016;8:6322.

7. Liu Y, Qian C, Yang M. Treatment patterns associated with ACR-recommended medications in the management of Fibromyalgia in the United States. J Manag Care Spec Pharm. 2016;22:263-71.

8. Park HJ, Moon DE. Pharmacologic management of chronic pain. Korean J Pain. 2010;23:99-108.

9. Kamble SV, Motlekar SA, D'souza LL, Kudrigikar VN, Rao SE. Low doses of amitriptyline, pregabalin, and gabapentin are preferred for management of neuropathic pain in India: is there a need for revisiting dosing recommendations?. Korean J Pain. 2017;30(3):183-91.

10. Apfel SC, Asbury AK, Bril V, Burns TM, Campbell JN, Chalk $\mathrm{CH}$, et al. Positive neuropathic sensory symptoms as endpoints in diabetic neuropathy trials. J Neurol Sci. 2001;189:3-5.

11. Abbott CA, Malik RA, van Ross ER, Kulkarni J, Boulton AJ. Prevalence and characteristics of painful diabetic neuropathy in a large community-based diabetic population in the U.K. Diabetes Care. 2011;34:2220-4.

12. Veves A, Backonja M, Malik RA. Painful diabetic neuropathy: Epidemiology, natural history, early diagnosis, and treatment options. Pain Med. 2008;9:660-74.

13. Bansal D, Bhansali A, Hota D, Chakrabarti A, Dutta P. Amitriptyline versus. pregabalin Pregabalin in painful diabetic neuropathy: A randomized double blind clinical trial. Diabet Med. 2019;26:1019-26.

14. Daousi C, MacFarlane IA, Woodward A, Nurmikko TJ, Bundred PE, Benbow SJ. Chronic painful peripheral neuropathy in an urban community: A controlled comparison of people with and without diabetes. Diabet Med. 2004;21:976-82.

15. Kaur H, Hota D, Bhansali A, Dutta P, Bansal D, Chakrabarti A. A comparative evaluation of amitriptyline and duloxetine in painful diabetic neuropathy: A randomized, double-blind, crossover clinical trial. Diabetes Care. 2011;34:818-22.

16. Gore M, Brandenburg NA, Dukes E, Hoffman DL, Tai KS, Stacey B. Pain severity in diabetic peripheral neuropathy is associated with patient functioning, symptom levels of anxiety and depression, and sleep. J Pain Symptom Manage. 2005;30:374-85.

17. Schmader KE. Epidemiology and impact on quality of life of postherpetic neuralgia and painful diabetic neuropathy. Clin J Pain. 2002;18:350-4.

18. Ghosh AK, Ghosh A, Kundu A, Das AK, Bhattacharya KB. Comparative study of efficacy and safety of pregabalin and gabapentin in neuropathic pain. Asian J Pharm Life Sci. 2012;2:64-71.

19. Franklin GM, Shetterly SM, Cohen JA, Baxter J, Hamman RF. Risk factors for distal symmetric neuropathy in NIDDM. The San Luis Valley Diabetes Study. Diabetes Care. 1994;17:1172-7.

20. Vinik AI, Tuchman M, Safirstein B, Corder C, Kirby L, Wilks $\mathrm{K}$ et al. Lamotrigine for treatment of pain associated with diabetic neuropathy: Results of two randomized, double-blind, placebo-controlled studies. Pain. 2007;128:169-79.

21. Collins SL, Moore RA, McQuay HJ, Wiffen P. Antidepressants and anticonvulsants for diabetic neuropathy and postherpetic neuralgia: A quantitative systematic review. J Pain Symptom Manage. 2000;20:449-58.

22. Dongre YU, Swami OC. Sustained-release pregabalin with methylcobalamin in neuropathic pain: an Indian real-life experience. Int J Gen Med. 2013;6:413-7.

23. Patel R, Dickenson AH. Mechanisms of the gabapentinoids and alpha 2 delta- 1 calcium channel subunit in neuropathic pain. Pharmacol Res Perspect. 2016;4(2):1-13.

24. Kumar K, Taylor RS, Jacques L, Eldabe S, Meglio M, Molet $\mathrm{J}$ et al. Spinal cord stimulation versus 
conventional medical management for neuropathic pain: a multicentre randomised controlled trial in patients with failed back surgery syndrome. Pain. 2007;132:179-88.
Cite this article as: Kancherla N, Babu GC, Singh H, Khandelwal M, Sharma N, Kuma MB.

Comparative study of safety and efficacy of pregabalin, gabapentin and amitriptyline in management of neuropathic pain. Int J Basic Clin Pharmacol 2021;10:64-9. 